\title{
Some Aspects of the Polar Regions*
}

\author{
By Prof. F. Debenham
}

\section{$\mathrm{T}$} HERE is now a vast literature of the polar regions, both north and south, but the proportion of those books and papers which deal with the subject on a broad basis is very small, and is certainly not easily accessible. In many of these books we are invited to conjure up the sensations of the polar explorer, to feel his frost-bites, to savour his pemmican, to glory in his pack-ice and his glaciers, even to die his death. Not the least part of our interest in polar work is due to these invitations so graphically offered to us in text and illustration. Much more rare is it to find a polar explorer viewing his territory as a whole, and trying to fit it into the scheme of the world in general. In a word, we are rather encouraged to regard the polar regions as places apart, extraneous to the real comity of the world. We will first consider the kind of value of the polar regions which appeals most quickly to the public.

\section{Trade and Trade Routes}

There is little need to sketch the history of man's attempts to achieve economic gain from the polar regions. From the days when Martin Frobisher attempted to find a quick route westwards to the Spice Islands via the North-West, and Barents a similar route eastward, down to more recent times when, though the routes had lost value, the products of hunting, fishing and mining attracted venturers with similar motives, the chief aim of promoters of polar expeditions has been one of ultimate gain. It is true that many of the leaders of the expeditions had little care for the commercial side, but the money that sent them forth was, in the greater number of cases, put out in the timehonoured hope of all ages that it would bring in interest in some form or another.

There is certainly such a thing as the romance of commerce in the North, for most of its industries have something peculiar and unusual about them. We may instance the cryolite mines of Ivigtut in Greenland-a strange mineral found in quantity nowhere else in the world, which however is almost essential to the large-scale production of aluminium. Again, until recently a large proportion of the ivory for use in northern China did not come from the present-day elephants of the rain forest belt of Asia, but from the mammoths of primeval times the tusks of which lay for many

- From the presidential address to Section $\mathbf{E}$ (Geography) of the British Association, delivered at Norwich on September 5. thousands of years buried in the mud of the great Siberian rivers flowing into the Arctic Ocean.

Romantic or not, the story of Arctic trade has a grim and melancholy side, in that several of its most promising ventures have died a slow and painful death by reason of the cupidity of man and his unwillingness to co-operate either to preserve life or even to preserve it sufficiently for his own benefit. The history of the whaling industry in the Arctic is an instance of this incapacity of man to co-operate in taking the most commonsense measures to cherish a valuable industry. There is every reason to hope that the day of nonco-operation has passed and that a similar fate to whaling in the Antarctic will not take place, for it is probably common knowledge that many bodies, in which we may include the League of Nations, the Norwegian whalers themselves and the "Discovery" Committee of the British Government, are at work in their various spheres to prevent any extermination of the southern whales, and at the same time to regularise an industry which, even in these days of synthetic materials, still has its vital uses to man. How large that industry now is may be gathered from the fact that the annual catch of whales in the southern seas is about 20,000 : how mindful it now is of its own future may be seen from the fact that whereas the average whale used to provide only 60 or 70 barrels of oil, it is now made to yield nearly 120 barrels of oil besides other products.

These products of hunting, fishing and mining were the natural resources of the North and were the first to be exploited, but quite recently a new factor in the commercial aspect of the North has come to the forefront. With the progress of longdistance aviation and the simple application of the principle of great-circle navigation, the idea of using these northern latitudes for passenger and even freight routes in the air has become not only prominent but also almost insistent.

Owing to the misleading projections on which most of our maps are constructed, it is not usually recognised that the most direct route between, say, Berlin and Montreal, or Glasgow and Winnipeg, is over Greenland, but it is so. It seems to be only a matter of time and the inevitable improvement of aeroplanes before some use is made of a route which was first investigated as to conditions by the Watkins Expedition of 1930.

Summing up this economic aspect of the polar regions, the warning may be given that even now, 
as in the past, there is a tendency to ascribe potential wealth merely on account of the existence of land masses. Indeed, even explorers, who should have known better, have been heard to speak glibly of the untapped mineral resources of the polar lands, neglecting to tell their public that though these resources undoubtedly exist, they are for the most part covered by thick ice sheets or rendered inaccessible by topography, or climate, or both. Quite a brief calculation, for example, would show that the proportion of the Antarctic continent available to the prospector and miner is to the total land mass in somewhat the same proportion as the area of the city of Norwich is to the whole of England.

Although the land can have little value in the Antarctic there is, strangely enough, a natural resource in the air which, however fantastic it may appear to us, may yet have a substantial interest for our descendants. It is a truism of science that we draw practically all our sources of power from the sun, either indirectly in the form of coal and oil, or directly in the form of water-power, in which the sun by evaporation has raised water to a height from which gravity, suitably used, returns power to us. Now, although water is one of the things of which there is a great scarcity in the polar regions, and the movement of ice masses can scarcely be handled by engineers, yet meteorological processes are doing the same thing for air, raising masses of air in one area which sink down in another, and so provide a source of power less tangible but just as real as that of water in a highland lake. The persistence, the strength and the frequency of the Antarctic blizzards compels anyone who has experienced them to feel that here is a vast source of power as yet untapped. May we be permitted to forecast that some day the miseries of the storm-bound parties of Mawson's expedition, when for a whole year the wind averaged gale force, may be atoned for by our descendants making use of this power when coal is scarce and oil exhausted, while all the waterpower in the temperate regions is fully harnessed? Compare the power in the well-known falls of Niagara, about 6,000 tons of water falling per second, with the power in the little-known Adélie Land, where an air river of at least 50 miles in width and probably some hundreds of feet in depth is moving outwards from the plateau at an average velocity of 50 miles per hour, or about $70 \mathrm{ft}$. per second for most of the year.

\section{The Poles as Sanatoria}

We pass now from the economic aspect of our subject to some others which have less appeal to the man in the street, but which must never be omitted in any consideration of a region by a geographer.

The consideration of the polar regions as a holiday resort for the citizens of crowded lands leads us naturally to a far greater value which has as yet scarcely been considered by civilisation, a value which indeed may yet prove to be more worthy of study than all those we have so far mentioned. It is reasonable to suppose that when some far-travelled medical man comes to write a book on the geography of diseases, we shall be able to come by a clear idea of where health is best to be sought. The ordinary geographer would, however, even now be able to make something of an essay on the distribution of healthiness over the world. Leaving out cities as unnatural, or at least unhealthy aggregations of humans, he would at once say that, on the whole, the most unhealthy parts of the world are in the tropics, though he would have to have a special category for tropical and oceanic islands, which as a rule are decidedly healthy. He would, if he were wise, consider that the steppe deserts are healthy zones; but probably he would decide that the temperate zone as a whole, provided it is not too far from the sea, is the healthiest belt of the world for man. It is almost certain that he would entirely forget that the polar regions are definitely the most healthy segments of the earth's surface, for the simple reason that the ordinary disease-bearers, whether they be rodents or insects or minute bacilli, find the conditions either impossible for existence or inhibitive.

But we are not concerned here so much with the healthiness of the zone as with its value from a remedial point of view, for we are certainly not going to migrate in millions to the Arctic just because we cannot there contract the diseases of our own lands. But what we may well pay attention to is the corollary to that healthiness, namely that many, though not all, of the diseases contracted in temperate climates can be cured by residence in the polar regions.

I am aware that it is more than dangerous, indeed provocative in the highest degree, for anyone outside the medical faculty to say how far special diseases are curable by residence in a pure air and a cold one. It seems, however, from the experience of sanatoria in the Alps, etc., that it is the sufferers from pulmonary diseases who are most likely to get benefit from such residence. The question will at once be asked as to what the polar regions can supply which is not already obtainable, say, in the Alps. For an answer to this question we must look to the medical men; but it does seem likely that residence in a vast territory free from germs or the conditions for their transport must, prima facie, be better than 
residence in an alpine region which is surrounded by, and is merely above, zones teeming with possibilities of disease. If this thesis is correct, and it is one which a small period of research could easily confirm or refute, then surely we are neglecting an aspect of the polar regions which is of major importance to mankind, more valuable than all the industries they will ever support.

To test the value of the suggestion there is needed research and experiment, most appropriately to be carried out under the auspices of one of those international bodies such as the Rockefeller Foundation, which has already done so much for remedial medicine. For assistance in carrying out this research there is needed tle sympathy of Governments, especially that of Norway, in the care of which is the most promising territory in the Arctic for that purpose, namely, Svalbard or Spitsbergen.

Let us remember too, before we allow hands of horror to be raised at the expense of such research, that in the past sums of money have been spent in Spitsbergen itself for the erection of an airship hangar and provision of the airship itself for a few hours' flight to the Pole, which would be sufficient to erect a hospital and run it for many years in an experiment which might be of permanent value to the world. We must be properly cautious as to results, but at the same time let us preserve our sense of proportion in the value to man of how we spend money in the polar regions. It is almost lamentable to consider the sums of money which have been spent in what may be understood by the term of 'stunt expeditions' and place those sums in contrast to the difficulty in raising money for such an object as this.

\section{WORLD METEOROLOGY}

We may now turn to yet another aspect of the polar regions, namely, the value to the scientific worker, both pure and applied, of the phenomena which are peculiar to these regions--phenomena well known to exist but the study of which is still in its early stages.

No doubt each science will claim the chief value of these phenomena for itself, but it is without any particular bias to one or the other that I should venture to place in the first rank the subject of meteorology as likely in the future to gain most by a prolonged and more intensive study in high latitudes.

We have spoken of the more or less permanent blizzards on parts of the Antarctic continent, and we ourselves live under the intermittent threat of depressions over Iceland. We can therefore, without much imagination, see that even if our weather is not actually manufactured at the polar ends of the world, it is profoundly affected by them. Meteorologists themselves have long been aware of this, and in two successive onslaughts, namely, in 1882 and in 1932, a determined effort was made to collect data simultaneously and widely within the precinets of the Arctic. The conclusions which have been drawn from these results are, as yet, scarcely in full circulation, but few meteorologists do not sigh for more and more data from the polar regions.

The phenomena of magnetism and aurora, which are somewhat akin to those of meteorology in that they occur in the atmosphere, are also best studied in high latitudes, where, too, the most promising investigations of the ionosphere seem to be likely.

\section{Geology}

When we come to the more earthly sciences, the immediate value to mankind is perhaps less evident. In the science of geology, for example, especially in its branch of tectonics, we cannot afford to do without close investigation of two segments of the earth comprising together nearly one tenth of the surface of the globe, and indeed the structure of the earth must become the more interesting the nearer one gets to its axis of rotation. The geologist has a hard task in lands where the rocks are usually buried beneath icecaps, and has to be more than usually ready with the inspired guess than in other parts of the world.

In the Antarctic in particular, the highest of all continents and the most closely hidden, there are obviously to be found keys to some of the major problems of earth structure. We may instance only one which, no doubt, is occupying the attention of the geologists of the British Graham Land Expedition at the present moment, an expedition which hopes to press far to the south of the Archipelago where they are wintering, and to determine why and where the folded ranges of South America and Graham Land merge into or butt against the faulted escarpments of the Australian sector of the Antarctic.

It is in these larger problems of geology that the polar geologist can give most assistance to science. It is not long since the papers, in America at all events, were full of the discovery of coal beds by Admiral Byrd's geologist within 300 miles of the South Pole, and it was interesting to see that this discovery, which however was originally made by the Shackleton party in 1908, moved the Press public to exclamations of wonder that such things could be. Nevertheless the great controversies of whether the Poles have shifted in the past, and whether the continents are drifting, must draw their best evidence, both for and against, near the axis of the earth. 
There has recently been published a fresh determination of the position of Sabine Island on the coast of north-east Greenland which tends to show that there is a definite westerly drift of some metres a year. Similar observations of Jan Mayen are even more startling. For these and other reasons, therefore, the geophysicist, whom we may call the mathematical cousin of the geologist, must keep his attention on the polar lands.

In the biological sciences also there are major problems to which the data of high latitudes alone can give the key, such as the drift of oceanic waters and the movements of plankton and their associated salts. The biologists, however, are already active in these investigations and need no spur to action. The many-sided character of the work of the "Discovery" Committee in this branch, over all the waters of the Antarctic ocean, is evidence of how carefully work on this aspect of the polar regions is being carried out.

\section{The Spirit of Exploration}

Lastly, I would consider yet another aspect of the polar regions, one which is perhaps more psychological than geographical, namely, their value as an outlet to that spirit of adventure and urge for exploration which has always been an attribute of man, and which will not diminish, however small the world may grow. It is a spirit which is at work equally in the small child climbing the apple tree, the schoolboy exploring his own small horizon, the undergraduate forming alpine clubs to scale the peaks of his own college, and the city clerk spending his week-ends living dangerously in sailing dinghy or on motor-bicycle.

In all of these there is a curious combination of an urge to test one's abilities and yet a desire for a secondary and more useful object in the deed itself, and this dual purpose is particularly evident in most of the young men who come to the Scott Polar Research Institute in Cambridge seeking ways in which to visit the Arctic.

Looking over the files of the geographical journals of the past few years, it is possible to see how many young men turn annually to the Arctic to satisfy their need for an outlet. If we include the official expeditions of Governments such as that of the Soviet, we shall find that every summer more than fifty groups of investigators go to the Arctic and, were it less expensive, the number would easily be trebled. Only a few of these groups go for purely scientific work, and still fewer for hunting alone. They are, in fact, as a rule imbued chiefly with a desire to see strange places and endure strange things, and only in a secondary way to bring back useful results. There has been of recent years a happy tendency for these groups to go and come back without undue fuss and publicity. I would suggest that this use of the Arctic as an outlet to a healthy and laudable desire is one which should not be left out of any assessment of values even though it must necessarily apply only to a small number of people.

\section{Problems of Plant Pathology}

$\mathrm{T}$ HE presidential address of Mr. F. T. Brooks to Section K (Botany) of the British Association delivered at Norwich on September 9 began in very pleasing vein by describing some of the outstanding contributions to botany made in East Anglia, wherein Norwich is an ancient and important city. It is fitting that upon such an auspicious occasion, the president of the Section should remind his audience of the deep roots of botanical lore in Great Britain-roots which go back to the enthusiasm of the ardent amateur. One heard the names of W. H. Burrell, W. A. Nicholson and Dr. C. B. Plowright coupled, in the recital of botanical progress in Norfolk, with more professional workers such as Dr. M. C. Cooke, Sir W. J. Hooker, Prof. F. W. Oliver, Prof. E. J. Salisbury, and many others.

The title of the address was "Some Aspects of Plant Pathology", and after showing that Norfolk farmers were among the first to realise the damage caused by disease, Mr. Brooks continued with a discussion of disease control by the use of resistant varieties of crop plants. The bad effects of several wilt diseases, the leaf-curl disease of cotton, and black rust of wheat can now be controlled with considerable success by planting new varieties with resistant qualities, but it seems very unlikely that all diseases will be amenable to control by this method. New diseases are continually appearing, parasitic fungi are amongst the most variable of living organisms, and the capacity for disease resistance in the host is very much in the nature of a mutation. The nicelyadjusted equilibrium between parasite and host can be upset when the latter mutates towards resistance, but the fungus can also vary, to give a new physiological form capable of attacking the host mutant. Thus the biological race for 